Military Technical College Kobry El-Kobbah, Cairo, Egypt

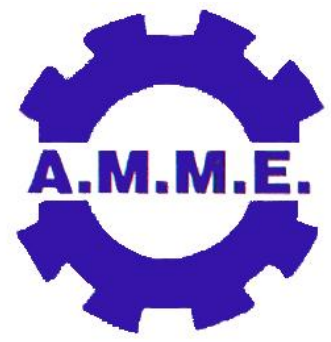

14th International Conference on Applied Mechanics and Mechanical Engineering.

\title{
Local buckling of axially compressed fully and partially stiffened GRP short columns: A comparison of Experimental and FE Analysis
}

By:

\author{
Amal Afifi* and Geoffery Turvey**
}

\begin{abstract}
Linear and nonlinear Finite Element (FE) analyses and experimental work on local buckling of un-stiffened, fully stiffened and partially stiffened full scale pultruded GRP profiles under uniform axial compression are presented. An investigation on improving the buckling capacity of I-section pultruded profile by bonding high modulus unidirectional CFRP strips to the top and bottom surface of the flanges along their free edges is carried out. The experimental buckling load for short columns with clamped ends (CC) have been evaluated using Southwell plots of deflection and bending strain test data. The experimental buckling loads have been also evaluated using the load versus endshortening graphs. The predicted buckling loads obtained from FE analyses are compared with the experimental results and good agreement has been achieved. It has been shown that, the use of stiffeners generally produces a significant increase in the local buckling load and a significant shift in the buckling mode.
\end{abstract}

Keywords: GRP columns, Buckling, FEA, CFRP, Stiffened columns

* Assistant Professor, Mechanical Design Department, Faculty of Engineering, Mataria, Helwan University Masaken Elhelmia 11718 Cairo. aam.afifi@gmail.com 
** Senior Lecturer, Engineering Department, Lancaster University, Lancaster United Kingdom LA1 4YR, g.turvey@lancaster.ac.uk 


\section{Introduction}

In recent years, the use of fibre-reinforced plastic (FRP) in civil engineering applications has increased dramatically. The increase in use may be attributed to their advantageous properties compared to conventional construction materials, eg. high specific strength and stiffness, low unit mass, high corrosion resistance and low thermal conductivity [1]. However, the first of these advantageous characteristics makes FRPs more susceptible to instability failure modes than conventional steel or aluminium structural components [2]. Consequently, the buckling behaviour of pultruded GRP profiles has been the subject of intensive research, especially over the past decade. A large number of analytical and experimental investigations of the buckling behaviour of open and closed-section pultruded GRP profiles subject to uniform uni-axial compression have been completed [314] and several design formulae have been proposed for predicting their buckling loads [15-17].

The buckling loads of pultruded GRP columns are limited by the low stiffness of the GRP material. One way of increasing the loads is to stiffen the profiles. This may be achieved in a variety of ways. For example, some of the GRP rovings could be substituted with CFRP rovings to produce a hybrid fibre pultruded profile. Whilst this is simple to achieve, it has the disadvantage that the stiffness is enhanced uniformly over the entire length of the profile and this may not be efficient from a structural performance standpoint [18]. An alternative approach is to bond stiffening material to the GRP profile. In the case of an I or $\mathrm{H}$-section profile, for example, the flange edges could be stiffened by bonding on CFRP strips over whole or part of their lengths [19]. As far as the authors' are aware this latter approach has not been investigated for pultruded GRP profiles and this has provided the motivation for the present investigation. Thus, the aim of this work is to enhance the buckling capacity of pultruded GRP short column with CFRP strips.

\section{Finite Element Models}

The FEA of unstiffened, partially stiffened and fully stiffened GRP columns were performed using the ANSYS software [22] to predict the buckling loads and mode shapes. The FE model of fully stiffened columns has been developed by dividing the flange of the column into two different areas one is the stiffened area and the other is the unstiffened area, as shown in Figure 1. The difference between the two areas is in the element properties. SHELL91 elements are used for both areas. For the stiffened area, the element layers are defined as having different thicknesses and materials whereas for the unstiffened area, elements have one thickness equal to the flange or web thickness of the I-section and one material. Each column was meshed uniformly. This element has eight nodes, each with six degrees of freedom. The element accounts for shear deformation effects and is also suitable for modelling laminated anisotropic materials. Hence, the strip stiffeners were treated as distinct lamina within the element. It should be appreciated, however, that the adhesive was ignored in the FE analysis. The element nodes were located on the mid-plane of the web and the inner of the flanges for unstiffened and stiffened columns in order to avoid the duplication of the cross-sectional area at the web and flange junctions.

The material properties used in the FE column models are listed in Table 1. These properties were derived from coupons tests for GRP and CFRP. However, the elastic transverse and in-plane shear moduli values were assumed as it was very difficult to test the CFRP strips neither in transverse direction nor the shear test. 
Table 1: Mechanical properties of the web of GRP I-section columns and CFRP strips

\begin{tabular}{|c|c|c|}
\hline Property & GRP & CFRP \\
\hline $\mathrm{E}_{11}(\mathrm{GPa})$ & 22.8 & 125 \\
\hline $\mathrm{E}_{22}(\mathrm{GPa})$ & 8.9 & 9 \\
\hline Poisson's Ratio $\mathrm{v}_{12}$ & 0.3 & 0.34 \\
\hline $\mathrm{G}_{12}(\mathrm{GPa})$ & 3.41 & 4.4 \\
\hline
\end{tabular}

The following end conditions are used in the ANSYS simulation of CC constraints for both linear and nonlinear analyses: See- Figure 2

I. Translational displacements along y and $z$ axes $U_{y}=U_{z}=0$ at $\mathrm{x}=0, \mathrm{~L}$

II. Translational displacement along $\mathrm{x}$-axis $U_{x}=0$ at $\mathrm{x}=\mathrm{L} / 2$

III. Rotational displacements around $\mathrm{x}, \mathrm{y}$, and $\mathrm{z}$ axes are suppressed i.e. $\phi_{x}=\phi_{y}=\phi_{z}=0$, at $\mathrm{x}=0, \mathrm{~L}$

IV. The translational displacements along $x$-axis at $x=0, L$ are coupled to ensure equal and opposite displacements at both ends

V. Apply point force at the central node of the web at $x=0, L$

Coupling of the nodes at each end ensures that all the nodes of the cross-section move together under the action of the concentrated load at the centred of the cross-section. This ensures that the column buckles under uniform end-shortening.

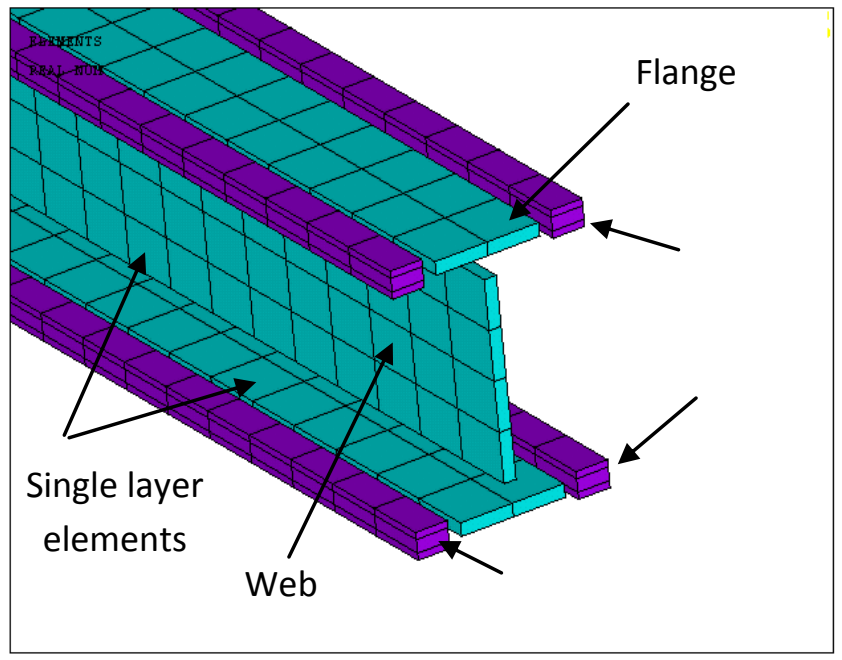

Figure 1: Modelling of fully stiffened Isection GRP columns

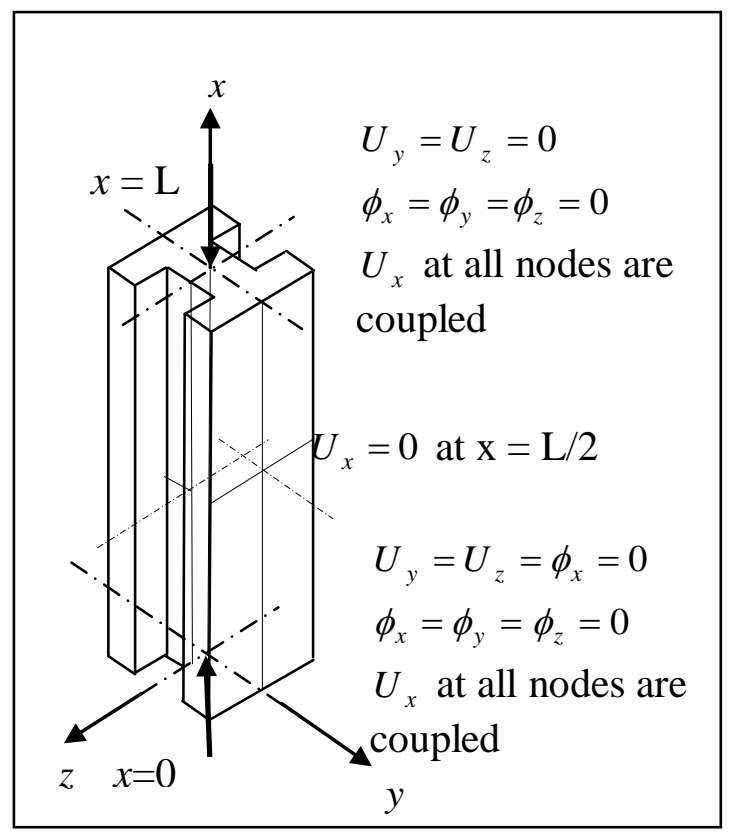

Figure 2: End conditions for $\mathrm{CC}$ end conditions

The FE buckling analysis starts with typical static loading to evaluate the stiffness matrix and then Eigen value problem were solved in ANSYS to evaluate the linear buckling load and the corresponding mode shapes in which imperfection of the column was neglected. The nonlinear FE analysis has been carried out to evaluate the buckling loads of the tested columns. In the FE analysis it was assumed that the column has an initial geometrical imperfection. The initial imperfections of the columns to be tested could have been measured, as suggested by many authors [23 and 24]. However, it is not possible to use the experimental initial imperfection data directly in the ANSYS FE software. Therefore, the initial imperfection used in the analysis was obtained from the linear 
buckling analysis. The shape of the geometrical imperfection was the same as the mode shape obtained from the linear buckling analysis and its amplitude was set to a small value to reflect the value which might exist due to manufacturing errors. It was found that the value of the nonlinear buckling load was very sensitive to the magnitude of initial imperfection. Many attempts were made to choose the optimum value. For the present nonlinear FE buckling analyses it was set to 0.002 of the amplitude of the mode shape of the buckled column obtained from the corresponding linear buckling analysis. This value, in conjunction with the number of iterations must be adjusted to obtain convergence of the nonlinear solution. The number of iterations was set to 100 for each time step in the Newton-Raphson or the Arc-length method used in the analysis. With the NewtonRaphson method converged solutions were obtained for unstiffened columns, but much longer processing times were required for stiffened columns. The Arc-length method was found to be suitable for both stiffened and unstiffened columns and converged solutions were obtained easily once suitable control parameters had been selected.

The linear buckling loads and mode shapes were obtained for the tested columns and then used to conduct the nonlinear analysis. The values of the buckling loads needed to be compared with the experimental buckling loads are those obtained from the nonlinear analysis. The value of the nonlinear buckling load can be obtained from the load-lateral deflection curves and/or the load-end shortening curves obtained from the nonlinear analysis. See Figure 3. Southwell method [25] has been employed to obtain the nonlinear buckling load from load-lateral deflection curve whilst the buckling load can be also obtained from the load-end-shortening curve at the point where the slope of the curve changes as shown in Figure $3 \mathrm{~b}$.

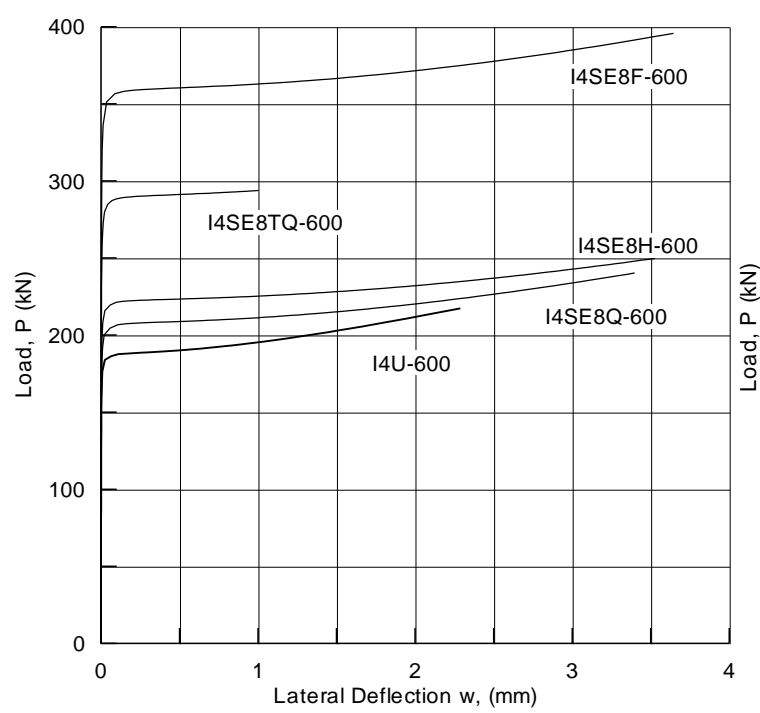

(a)

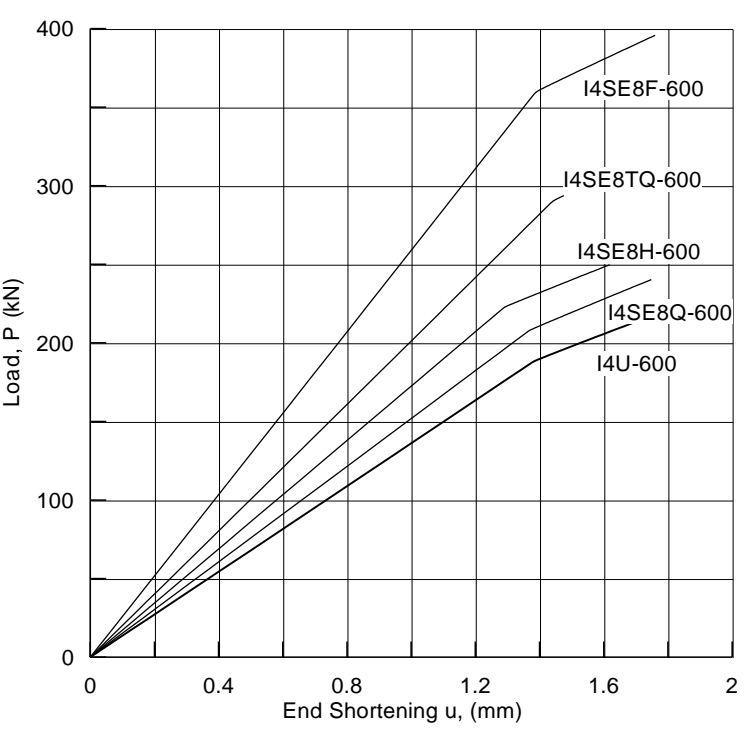

Figure 3: Nonlinear FE results (a) Load-Lateral Deflection curves (b) Load-end-shortening curves for stiffened and unstiffened columns

\section{Experimental Work}

All of the columns tested were 4 inch $(102 \times 102 \times 6.35) \mathrm{mm}$ GRP EXTREN 500 series [20] I-profiles (I4). The columns were divided into two groups: unstiffened columns (U) and stiffened columns (S). In the latter group, the stiffeners were bonded along the edges $(E)$ of the flanges on both faces, i.e 8 stiffeners were used per column; thus the part of the 
code for the edge stiffened columns was (SE8). Table 2 shows columns dimensions and stiffeners lengths. In the present series of column tests four symmetrically stiffener lengths were used:

1. Full length stiffeners $(F)$

2. Half-length stiffeners $(\mathrm{H})$

2. Three-quarter length stiffeners (TQ)

3. Quarter-length stiffeners $(Q)$

To evaluate accurately the load at which a column begins to buckle, it must be instrumented with sensors to record deformations during loading. The sensors must be placed at positions on the column where large and readable deformations occur. The buckling load can be evaluated using various test data such as end-shortening, lateral deflection and bending strain [10,13, and 21]. In the current work the columns were instrumented with axial and lateral displacement transducers and strain gauges, located where the maximum deflections are expected. To determine these location a preliminary FE analyses were carried out for each column. Table 3 shows the locations of the strain gauges and displacement transducers on each column.

Table 2: Columns codes and their interpretations

\begin{tabular}{|c|l|}
\hline $\begin{array}{c}\text { Column } \\
\text { Code }\end{array}$ & \multicolumn{1}{|c|}{ Description } \\
\hline I4U-600 & Unstiffened $L=600 \mathrm{~mm}$ \\
\hline I4SE8Q-600 & $\begin{array}{l}\text { Partially stiffened } L=600 \mathrm{~mm} L_{s}= \\
150 \mathrm{~mm}\end{array}$ \\
\hline 14SE8H-600 & $\begin{array}{l}\text { Partially stiffened } L=600 \mathrm{~mm} L_{s}= \\
300 \mathrm{~mm}\end{array}$ \\
\hline $\begin{array}{c}\text { 14SE8TQ- } \\
600\end{array}$ & $\begin{array}{l}\text { Partially stiffened } L=600 \mathrm{~mm} L_{s}= \\
450 \mathrm{~mm}\end{array}$ \\
\hline I4SE8F-600 & $\begin{array}{l}\text { Fully stiffened } L=600 \mathrm{~mm} L_{s}=580 \\
\mathrm{~mm}\end{array}$ \\
\hline
\end{tabular}

Table 3: Instrumentation used on the unstiffened and stiffened GRP columns

\begin{tabular}{|c|l|c|}
\hline $\begin{array}{c}\text { Column } \\
\text { Code }\end{array}$ & \multicolumn{1}{|c|}{ Description of Instruments } \\
\hline I4U-600 & $\begin{array}{l}\text { 6 strain gauges were used, G1, G2 back } \\
\text { to back and } \mathrm{G} 3, \mathrm{G} 4 \text { back to back on the } \\
\text { flanges. G5, G6 back to back at the } \\
\text { centre of the web. All gauges were at the } \\
\text { mid-height of the column. Two lateral } \\
\text { deflection transducers T1, T2 were placed } \\
10 \mathrm{~mm} \text { in from the edge of the flanges in } \\
\text { buckled mode shape } \\
\text { opposite directions at the mid-height of } \\
\text { the column. }\end{array}$ \\
\hline $\begin{array}{l}\text { 8 strain gauges were used, G1, G2 back } \\
\text { to back and G3, G4 back to back on the } \\
\text { flanges } 180 \mathrm{~mm} \text { from the top and bottom } \\
\text { of the column.G5, G6 and G7, G8 back to } \\
\text { back were 180 mm from the column ends } \\
\text { on the web. Two lateral deflection } \\
\text { transducers T1, T2 were placed } 10 \text { mm in }\end{array}$
\end{tabular}




\begin{tabular}{|l|l|l|} 
& $\begin{array}{l}\text { from the edge of the flanges in opposite } \\
\text { directions } 180 \mathrm{~mm} \text { from the bottom of the } \\
\text { column. }\end{array}$ & \\
\hline
\end{tabular}

Test data were recorded using the Strain Smart system which allows simultaneous recording of load and sensors data. Figure 4 shows experimental data in the form of lateral deflection, end-shortening and strains of the web for different columns.

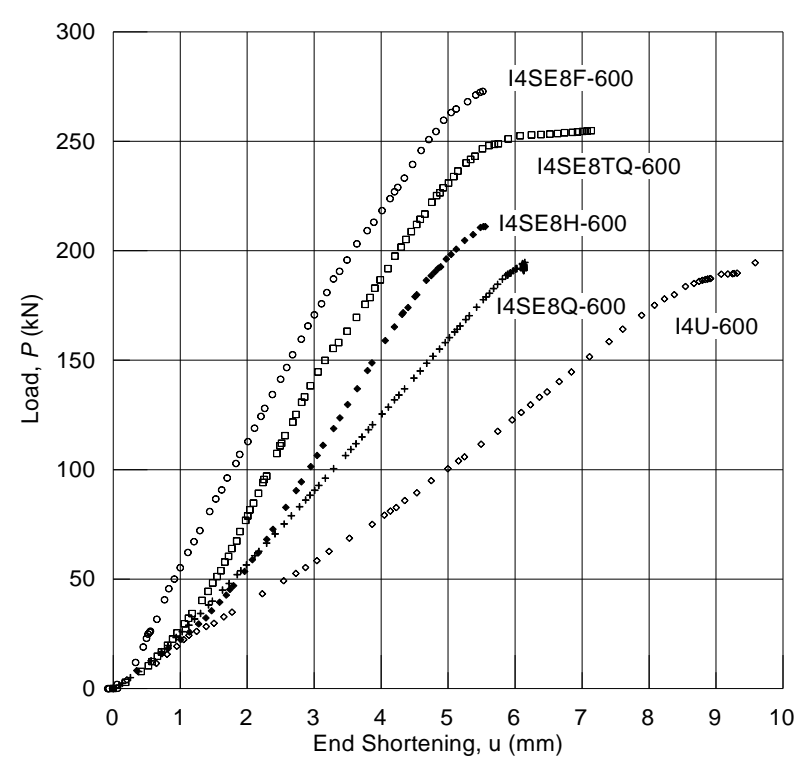

(a)

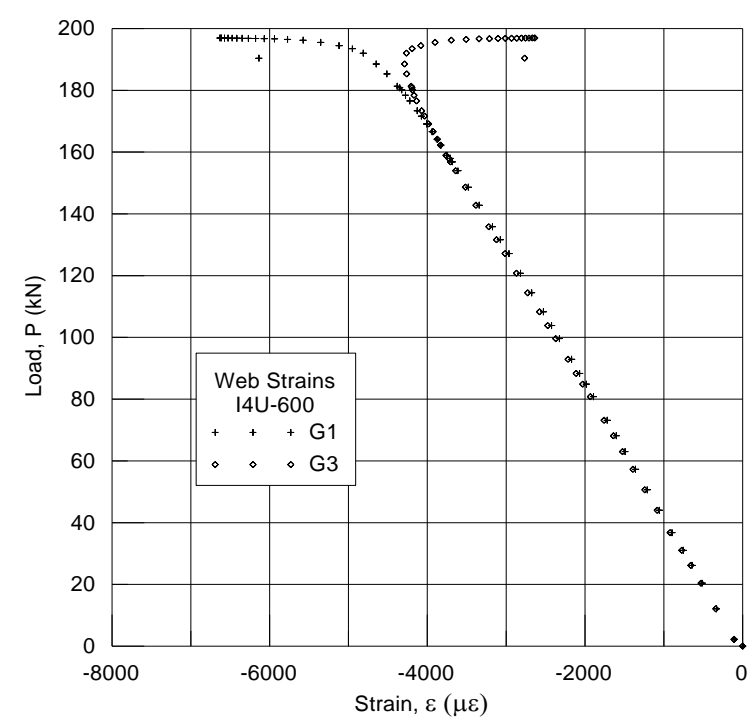

(c)

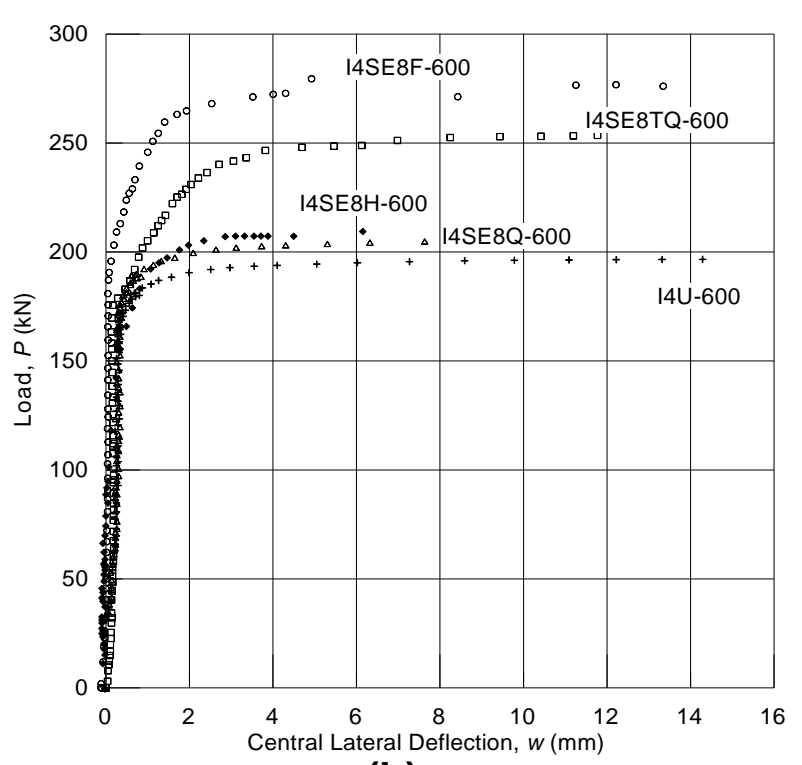

(b)

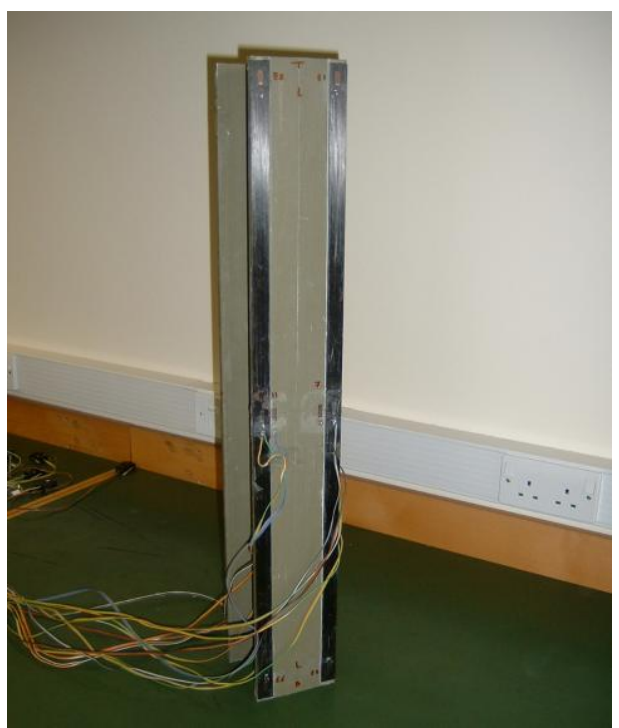

(d)

(c)

(d)

Figure 4: Test data recorded for $14-600$ columns with CC ends: (a) Load-lateral deflection, (b) Load-end shortening (c) Web strains for 14U-600 (d) Instrumented fully stiffened column

Figure 5 shows the buckled columns during the test. The buckling modes are clearly observed during the tests. 


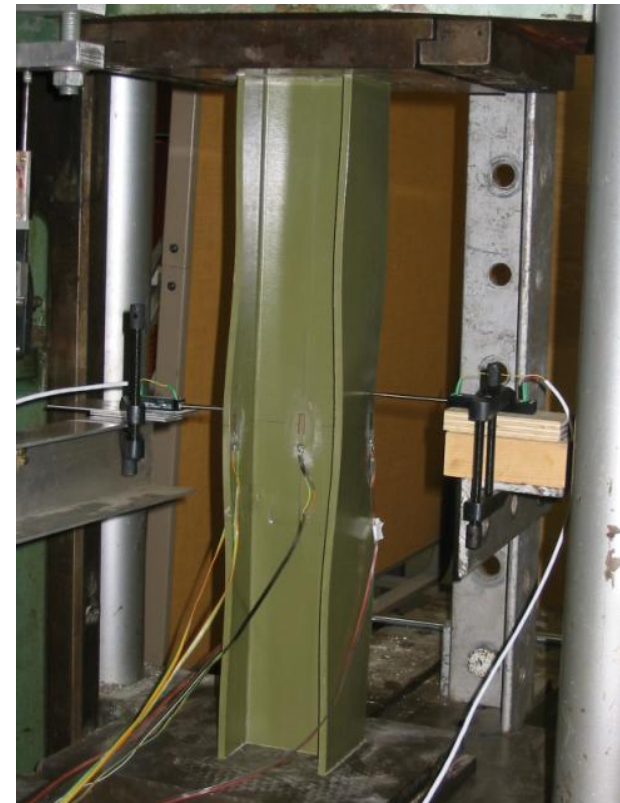

(a)

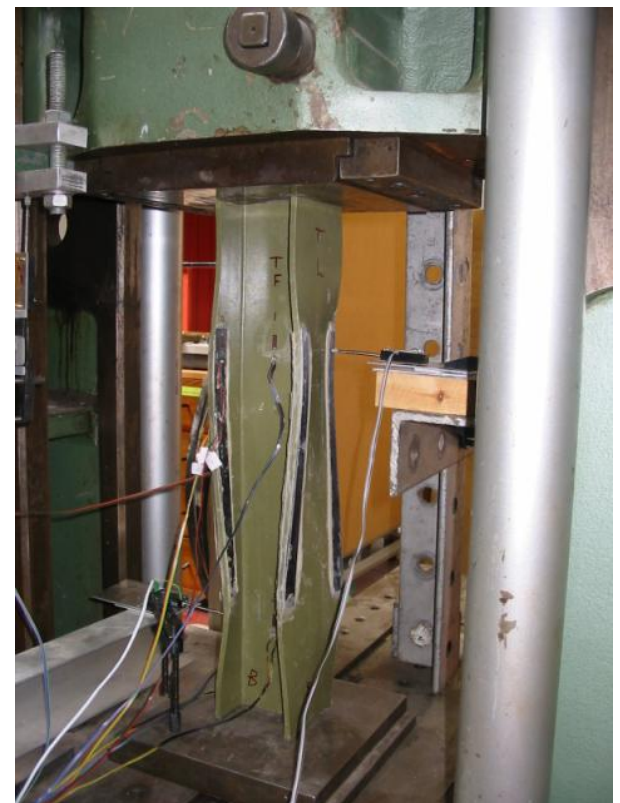

(b)

Figure 5: Buckling mode shapes

(a) Unstiffened column 14U-600 (b) Partially stiffened columns I4SE8H-600

\section{Results and Discussions}

An average value of the buckling load was calculated from the values obtained from the test data. These average values are used in the comparisons between FE predicted and experimental buckling loads. Figure 6 shows the buckling loads obtained from the Southwell plots (load-lateral deflection and bending strains) and from the load end shortening curves.

Buckling loads were evaluated using different types of test data as indicated earlier. The buckling loads derived from the end-shortening data and those obtained from the Southwell plots of the lateral deflection, web bending strain and flange bending strain data are denoted as $P_{u}, P_{w}, P_{\varepsilon_{b}^{w}}$ and $P_{\varepsilon_{b}^{f}}$ respectively and are compared in Table 4. In some cases, test data could not be used to evaluate the buckling load, due to the scatter in the data. These are indicated by (-) in Table 4.

Table 4: Comparison between the buckling loads calculated using different sets of buckling test data

\begin{tabular}{|l|l|l|l|l|l|}
\hline Column Code & $\begin{array}{c}\text { End- } \\
\text { Enortening } \\
\text { Buckling } \\
\text { Load (kN) }\end{array}$ & \multicolumn{2}{|l|}{ Southwell Buckling Load (kN) } & $\begin{array}{c}\text { Average } \\
\text { Buckling } \\
\text { load } \\
\text { (kN) }\end{array}$ \\
\hline & $P_{u}$ & $P_{w}$ & $P_{\varepsilon_{b}^{\prime \prime}}$ & $P_{\varepsilon_{b}^{f}}$ & $P_{E x p}$ \\
\hline I4U-600 & 192.2 & 197.73 & 197.73 & 198.38 & 196.51 \\
\hline I4SE8Q-600 & 195 & - & 196.66 & 214.2 & 201.95 \\
\hline I4SE8H-600 & 230 & 229.7 & 229.7 & 229.11 & 229.62 \\
\hline I4SE8TQ-600 & 251 & 249.06 & 248.87 & 250.63 & 249.89 \\
\hline 14SE8F-600 & 252 & 253.66 & 252.64 & 247.63 & 251.48 \\
\hline
\end{tabular}



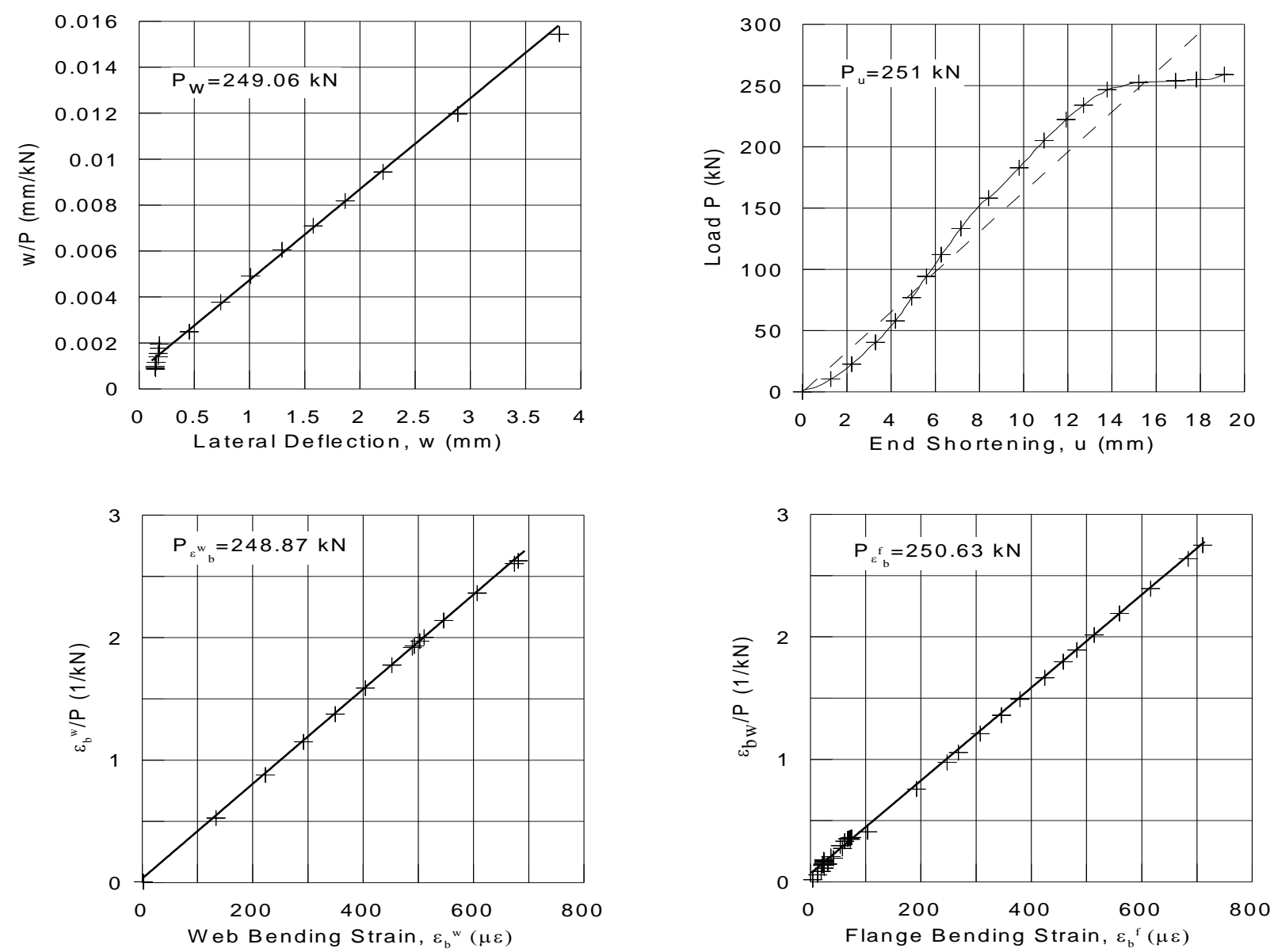

Figure 6: Buckling load evaluation using Southwell plots: (a) lateral deflection, (b) web end shortening, (c) bending strain and (d) flange strain data for an I4SE8TQ-600 column

A comparison between the buckling loads obtained experimentally and those obtained with the nonlinear FE analysis are presented in Table 5 . The following observations have been noted for the tested columns and the obtained results:

1. Significant improving of the buckling loads was obtained by bonding strips of CFRP on the flanges of the columns. In some cases (Fully stiffened) the FE buckling load has been increased to approximately $100 \%$ of the unstiffened value, The experimental ratio was about $30 \%$ this was due to the debonding of the strips and failure of the adhesive material.

2. The predicted FE buckling modes match those observed in the tests.

3. The CFRP stiffeners tended to deboned from the column flanges at loads ranging between $240-280 \mathrm{kN}$.

4. Local buckling modes observed in some column tests differed from those predicted by the FE analysis. The difference in the number of half - waves buckles was attributed to stiffeners debonding which changed the stiffness of the column flanges during the column tests

5. For the unstiffened short column $14 \mathrm{U}-600$, the effect of the end conditions on the buckling load obtained experimentally was negligible, whereas the predicted FE buckling loads differ by $2.15 \%$.

6. The predicted nonlinear FE buckling loads were higher than the experimental buckling load for approximately $60 \%$ of the columns. 
7. FE predictions of the buckling loads of columns with high stiffening ratios were significantly higher than the experimental buckling loads. This could be due to the assumption in the FE analysis of perfect bonding of the stiffeners to the column flanges, and to debonding of the stiffeners at high load.

Table 5: Comparison between the experimental buckling loads and those obtained by nonlinear FE and exact analyses

\begin{tabular}{|c|c|c|c|c|}
\hline Column Code & \multicolumn{4}{|c|}{ Buckling load (kN) } \\
\hline & Analytical & $\begin{array}{c}\text { Non-Linear } \\
\text { FE }\end{array}$ & Experimental & $\begin{array}{l}\text { Buckling Mode } \\
\text { FE/Experimental }\end{array}$ \\
\hline $14 U-600$ & 198.9 & 190 & (CC 196.51) & Local/Local $m=3 / 3$ \\
\hline I4SE8Q-600 & - & 209 & 201.95 & Local/Local $m=2 / 3$ \\
\hline I4SE8H-600 & - & 222 & 229.62 & Local/Local $m=2 / 3$ \\
\hline I4SE8TQ-600 & - & 291 & 249.89 & Local/Local $m=2 / 2$ \\
\hline I4SE8F-600 & - & 361 & 251.48 & Local/Local $m=2 / 2$ \\
\hline
\end{tabular}

\section{Conclusions:}

In the current work, linear and nonlinear FE analysis has been conducted to investigate the buckling load enhancement using strip stiffeners on the flanges of pultruded I-shaped GRP columns. Southwell plots were used to evaluate buckling loads from nonlinear FE load - deflection curves and from the experimental load - deflection and load - bending strain curves of the web and flanges of the column. Load - end-shortening curves were also used to determine the buckling load. A local buckling mode with different numbers of half-waves $(\mathrm{m})$ occurred in stiffened and unstiffened $600 \mathrm{~mm}$ columns. The buckling modes predicted by the FE simulations of the column tests were the same for most of the columns tested. However, some differences in the number of half - waves were observed in the $600 \mathrm{~mm}$ stiffened columns which were due to the debonding of the stiffeners which was assumed perfect bonding in the FE analysis. Buckling loads obtained from the experimental load - end-shortening curves were slightly lower than those obtained from Southwell plots for the majority of the columns tested. The same results trend was observed with the nonlinear FE buckling results. The average buckling loads obtained experimentally were lower than the average nonlinear FE buckling loads for short columns.

\section{References}

[1] Barbero, E. J. 1998. "Introduction to composite materials design" Taylor and Francis, Inc.

[2] Allen, H. G. and Bulson, P. S., 1980. "Background to buckling", McGraw-Hill Book Company UK

[3] Zureick, A. and Scott,D., "Short term behaviour and design of fibre-reinforced polymeric slender members under axial compression", Journal of Composites for Construction, 1997.

[4] Lane, A., "Finite element buckling analysis of fibre reinforced plastic columns", Fourth Year Project Report, University of Warwick, May, 1997.

[5] Lee,D. J. and Hewson, P.J., "The use of fibre-reinforced plastics in thin-walled structures", 1979.

[6] Vakenier, A.R., Zureick, A. and Will, K.M., "Prediction of local flange buckling in pultruded shapes by finite element analysis", Proceedings of the ASCE Special Conference on Advanced Composite Materials in Civil Engineering Structures, Las Vegas, Nevada, 1991, pp 302-312. 
[7] Brown, N. D., Mottram, J. T. and Anderson, D., "The behaviour of columns for the design of pultruded frames: tests on isolated columns", Second International Conference on Composites in Infrastructure. 1998.

[8] Mottram, J. T., Brown, N. D. and Lane, A., "The analysis of columns for the design of pultruded frames: isolated centrally loaded columns", ECCM-8, 1998, pp. 235242.

[9] Scott, D. W. Yoon, S. J. and Zureick, A., 1992. "Full scale testes on concentricity loaded fibre-reinforced pultruded columns" Proceedings of the American Society of Civil Engineers Material Engineering Congress, Atlanta, Georgia August 10-12.

[10] Yoon, S. J. , Scott, D. W, and Zureick, A., 1992, "Experimental investigation of the behaviour of concentrically loaded pultruded columns" Advanced Composite Materials in Bridges and Structures 1992.

[11] Zureick, A. and Shih, B 1998. "Local buckling of fibre-reinforced polymeric structural members under linearly- varying edge loading - Part 1 theoretical formulation" Composite Structures, V. 41,, pp 79-86.

[12] Pecce, M., Lazzaro, F. and Cosenza, E., 1998. "Local buckling of FRP profiles: experimental results and numerical analysis", ECCM 8, pp 331-338.

[13] Turvey, G. J. and Zhang, Y., 2006. "A Computational and Experimental Analysis of the Buckling, Postbuckling and Initial Failure of Pultruded GRP Columns" Computers and Structures, 84 (22-23) 1527-1537.

[14] Turvey, G. J. and Zhang, Y., 2004. "local buckling of Axially compressed, pultruded GRP, WF-section, short columns-comparsion of experimental and FE analysis buckling loads" Applied mechanics and materials, 1-2, 87-92, 2004.

[15] Mottram, J. T., Brown, N. D. and Lane, A., 1998. "The analysis of columns for the design of pultruded frames: isolated centrally loaded columns " ECCM-8, pp 235242.

[16] Mottram, J. T., 2004. "Determination of critical load for flange buckling in concentrically loaded pultruded columns" Composites Part B: Engineering, 35, pp 35-47.

[17] Barbero, E. J. and Tomblin, J., 1994. "A phenomenological design equation for FRP columns with interaction between local and global buckling" Thin-Walled Structures, 18, pp 117-131.

[18] G. J. Turvey, G.J and Afifi, A., Euler Buckling of Partially Stiffened Pultruded GRP Columns: A Comparison of Shell Finite Element and Beam-Column Model, proceedings of Advanced Polymer Composites for structural applications in Construction, ACIC, 20-22 April, 545-552, 2004

[19] Afifi, A., Buckling Analysis of Stiffened Pultruded GRP Columns and Plates, PhD thesis, Lancaster university, UK, 2007

[20] Anon: EXTREN® 500 Pultruded GRP products. www.strongwell.com

[21] Yoon, S. J., 1993. "Local buckling of pultruded shape columns" PhD Thesis, GIT, USA.

[22] Anon: 2003-2006. "ANSYS V.10 Documentation" ANSYS Inc, USA

[23] Hashem, Z. A. and Yuan, R. L., 2000. "Experimental and analytical investigations on short GFRP composite compression members" Composites Part B, 31, pp 611618.

[24] Hashem, Z. A. and Yuan, R. L., 2001. "Short vs. long column behaviour of pultruded glass-fibre reinforced polymer composites" Construction and Building Materials, 15, pp 369-378.

[25] Southwell, R. V., 1931. "On the analysis of experimental observations in problems of elastic stability". 